\title{
Effect of Rolling Reduction on Microstructure and Property of Ultrafine Grained Low-Carbon Steel Processed by Cryorolling Martensite
}

\author{
Qing Yuan, Guang $X u$ * $\mathbb{D}$, Sheng Liu, Man Liu, Haijiang Hu and Guangqiang Li \\ The State Key Laboratory of Refractories and Metallurgy, Hubei Collaborative Innovation Center for Advanced \\ Steels, Wuhan University of Science and Technology, 947 Heping Avenue, Qingshan District, \\ Wuhan 430081, Hubei, China; 15994235997@163.com (Q.Y.); liusheng@wust.edu.cn (S.L.); \\ m13971287356@163.com (M.L.); huhaijiang@wust.edu.cn (H.H.); liguangqiang@wust.edu.cn (G.L.) \\ * Correspondence: xuguang@wust.edu.cn; Tel.: +86-027-6886-2813
}

Received: 19 June 2018; Accepted: 3 July 2018; Published: 5 July 2018

check for updates

\begin{abstract}
A novel method of cryorolling martensite for fabricating ultrafine grained low-carbon steel with attractive strength was proposed. The results indicate that ultrafine-grain structured steel could be manufactured by cryorolling and the subsequent annealing of martensite. The mean ferrite size of $132.0 \mathrm{~nm}$ and the tensile strength of $978.1 \mathrm{MPa}$ were obtained in a specimen with a reduction of $70 \%$ in thickness. There were peak value and valley value in the strength and grain size of ferrite with the increase of reduction from $50 \%$ to $80 \%$, respectively. The further growth of ferrite grain at $80 \%$ reduction is attributed to the heavier distortion energy at large reduction, which activates the secondary recrystallization of ferrite. Furthermore, the distribution of ferrite grains became more uniform with increasing of reduction from $50 \%$ to $70 \%$. Additionally, the amount of lamellar dislocation cell substructure increased with the reduction at liquid nitrogen temperature.
\end{abstract}

Keywords: cryorolling; reduction; ultrafine grain; secondary recrystallization; high strength

\section{Introduction}

Common low-strength steel cannot meet the requirements of most manufacturing and production industry in modern society [1,2]. The research and fabrication of high strength steel has become an important topic [3,4]. In recent years, ultrafine-grained structure steel with grain size below $1 \mu \mathrm{m}$ has shown the prospect of high strength and toughness with traditional steel compositions [5,6]. For the fabrication of ultrafine-grained structure steel, both severe plastic deformation strategies (SPD) and advanced thermomechanically controlled processes (TMCP) were applied [7,8]. Severe plastic deformation strategies (SPD) usually use large accumulated plastic strain, which is larger than four at room or elevated temperatures [9]. The large accumulated plastic strain causes more loads for the equipment. In addition, this method is only suitable for small size samples. Classic SPD techniques include equal-channel angular pressing (ECAP) [10-12], accumulative roll bonding (ARB) [13-15], mechanical milling (MM) [16,17], and high-pressure torsion (HPT) [18-20], etc. When compared with severe plastic deformation strategies, advanced thermomechanically controlled processes employ a relatively low accumulated strain in the range of about $0.8-3.0$. Moreover, this method can be somewhat more easily optimized to operate in temperature regimes where they employ phase transformation and controlled cooling. One effective way with a small accumulated strain to fabricate ultrafine-grained structure steel through cold rolling and annealing of a martensitic starting microstructure was first proposed by Tsuji et al. [21] (Fe-0.13 wt.\%C). The final microstructure was ultra-fined ferrite grains with average grain size of $180 \mathrm{~nm}$ and inhomogeneously precipitated carbides. The tensile strength and elongation of the ultrafine-grained structure steel was $870 \mathrm{MPa}$ and $20 \%$, respectively. 
Currently, more attention has been paid to the study on the cold rolling and annealing of a martensitic starting microstructure due to the availability of grain refinement of this method. Hosseini et al. [22] obtained nano/ultrafine grained low carbon steels with mean grain size of $0.65 \mu \mathrm{m}$ by the compression of a martensitic structure and following the high temperature annealing process (Fe- $0.13 \mathrm{wt} . \% \mathrm{C}$ ). The ultimate strength of $810 \mathrm{MPa}$ was reported by annealing at $600{ }^{\circ} \mathrm{C}$ for 120 s. Similarly, Ashrafi et al. [23] successfully produced ultrafine ferrite microstructure by $65 \%$ cold compression of martensite, followed by annealing at an intermediate temperature. The mean size and hardness were $1.8 \mu \mathrm{m}$ and $210 \mathrm{HV}$, respectively. Additionally, the recrystallization activation energy was calculated to be $83 \mathrm{~kJ} / \mathrm{mol}$. Ueji et al. [24] and Bao et al. [25] performed similar investigations on cold rolling and annealing of a martensitic starting microstructure.

In order to further refine the grain size and improve the tensile strength, many possible explorations were conducted. For example, Jing et al. [26] fabricated nanocrystalline steel sheets by a combination process of quenching, aging, heavy cold rolling, and recrystallization. Li et al. [27] utilized the ice brine-quenching method before cold rolling and annealing to obtain superfine lath martensite grain. Hamad et al. [28] applied a differential speed rolling (DSR) process to fabricate ultrafine-grained steel, followed by annealing at $425^{\circ} \mathrm{C}$ and $625^{\circ} \mathrm{C}$ for $60 \mathrm{~min}$.

It is known that the process of recovery could be hindered by decreasing deformation temperature, by which the rich deformation defects and efficient accumulated strain are obtained. This is because the atoms diffusion ability is dramatically weakened at the liquid nitrogen temperature, leading to the restraint in the motion and annihilation of heat activated dislocations. Therefore, the accumulated dislocation defects become more and more, showing a serious work-hardening behavior. Thus, it can offer an advantageous condition for the refinement of grains and the acceleration of subsequent recrystallization. However, most investigations were performed at room temperature or warm temperature, and few studies that were concerned on the cryorolling of carbon steels. Moreover, less attention was paid on the relationship between rolling reduction and grain size and mechanical property in carbon steel. Therefore, in the present study, cryorolling martensite starting microstructure and the subsequent annealing was performed to fabricate ultrafine-grain structured steel. The key point of this process is that martensite is rolled at liquid nitrogen temperature. Results could enrich the fabrication theory of ultrafine-grain structured steel.

\section{Materials and Methods}

The experimental material is commercial low-carbon steel with a tensile strength of $435 \mathrm{MPa}$, taken from a hot strip plant. The composition of this steel is Fe-0.165C-0.211Si0.448Mn-0.014P-0.013S-0.002Als (wt.\%). The dimensions of specimens prepared to fabricate ultrafine grains were $3 \mathrm{~mm}$ in thickness, $15 \mathrm{~mm}$ in width, and $90 \mathrm{~mm}$ in length. Figure 1 shows the schematic diagram of fabrication of ultrafine grain by cryorolling low-carbon steel. The specimens were austenitized at $1050{ }^{\circ} \mathrm{C}$ for $30 \mathrm{~min}$, followed by water quenching to obtain martensitic starting microstructure. Before the cryorolling process, all of the martensitic specimens were immersed in liquid nitrogen for about $30 \mathrm{~min}$, ensuing that the temperature of specimens were in accord with that of liquid nitrogen. Then, the specimens were rapidly rolled on a two-high mill with $310 \mathrm{~mm}$ in roll diameter. About $10 \%$ reduction was realized in each pass and the total reduction were $50 \%(\varepsilon=0.8), 60 \%(\varepsilon=1.06)$, $70 \%(\varepsilon=1.5)$, and $80 \%(\varepsilon=1.8)$, respectively. The specimens were immersed in liquid nitrogen again for $15 \mathrm{~min}$ before further reduction after each pass. As the relative small size of the specimen, $15 \mathrm{~min}$ in liquid nitrogen was long enough for the specimen to regain the liquid nitrogen temperature. There were no cracks on the specimens during the cryogenic deformation process. No lubrication was used during rolling. Moreover, ambient temperature rolling test was performed by $50 \%$ strain in order to compare the microstructure before annealing. Finally, the cryorolled samples were subsequently annealed at $500{ }^{\circ} \mathrm{C}$ for $30 \mathrm{~min}$ before being air cooled to the ambient temperature. 


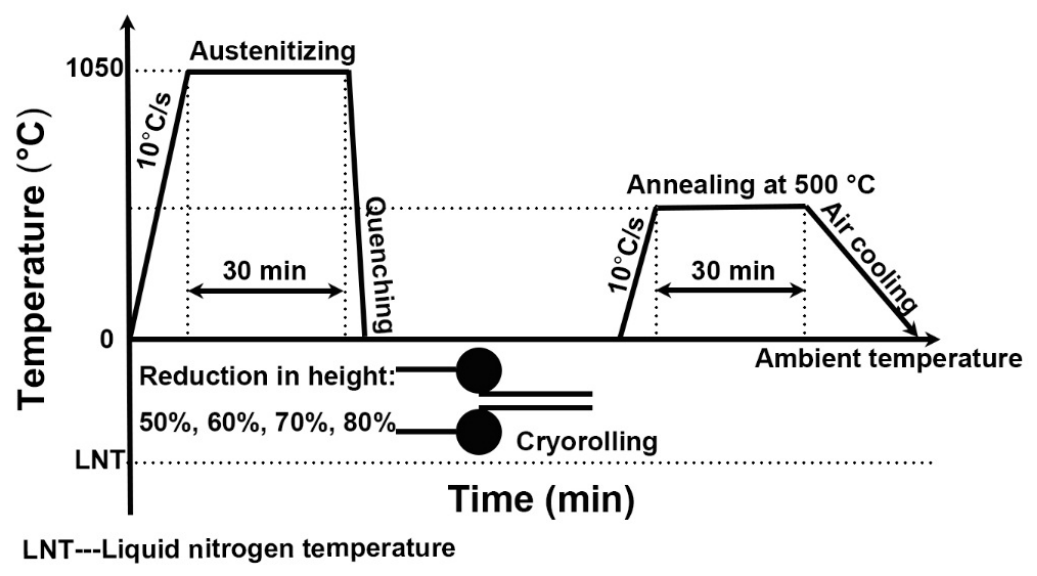

Figure 1. Schematic of fabrication of ultrafine grain by cryorolling low-carbon steel.

For microstructure observation, all of the specimens were mounted in resins, ground using $\mathrm{SiC}$ papers with 240-2000 grit, and then polished in an $\mathrm{Al}_{2} \mathrm{O}_{3}$ slurry on a metallographic polishing machine (YMP-2, Nanguang electronic technology, Suzhou, China). The microstructure examination of specimens was conducted on an optical microscopy (OM, Zeiss, Oberkochen, Germany) and a Nova 400 Nano scanning electron microscope (SEM, Hillsboro, OR, USA) operated at $20 \mathrm{kV}$ accelerating voltage. The dislocation distribution after rolling was observed using a JEM-2100F transmission electron microscope (TEM, JEOL, Tokyo, Japan). All of the microstructures were observed from rolling direction (RD). X-ray diffraction (XRD, Panalytical, Almelo, The Netherlands) was applied to analyze the precipitations. The grain dimensions were measured by Image Pro-plus software 6.0 (Media Cybernetics, Duluth, GA, USA) on the basis of the mean linear intercept method (MLIM). Some images and more than 120 grains were measured for improving the accuracy. Tensile tests were carried out at ambient temperature with a cross-head speed of $1 \mathrm{~mm} / \mathrm{min}$ on a UTM- 4503 electronic universal tensile machine (Instron, Norwood, MA, USA). The tensile direction was in keeping with the rolling direction. The dimension of the gauge part in tensile specimens was $1.2 \mathrm{~mm}$ wide, $0.6 \mathrm{~mm}$ thick, and $5 \mathrm{~mm}$ long. Duplicate tests were made for each tensile test to ensure reproducibility.

\section{Results and Discussion}

\subsection{Microstructure Evolution}

Figure 2 gives the original microstructure of the tested low-carbon steel. It is observed that the original microstructure mainly consisted of ferrite $(\mathrm{F})$ and pearlite $(\mathrm{P})$. Ferrite distributed in equiaxed polygon morphology and pearlite with irregular shape located in the adjacent to ferrite. Figure $2 \mathrm{c}, \mathrm{d}$ were obtained by the color aberration function in Image Pro-plus software 6.0, representing the volume fractions (areas) of ferrite and pearlite, $87.1 \pm 6.9 \%$ and $12.9 \pm 3.3 \%$, respectively. Several images with the same magnification were used to ensure the accuracy of the measurement. The average values were taken as the final volume fractions of ferrite and pearlite.

After water quenching, very fine lath martensite was obtained in Figure 3. It has been proved by Electron Backscattered Diffraction (EBSD) that many high-angle boundaries with misorientations that were larger than $15^{\circ}$ facilitating the refinement of grain during following an annealing process existed in martensitic microstructure $[13,21,24]$. Except for martensitic microstructure, dual phase structure with ferrite and martensite $[22,29,30]$ was utilized to develop bimodal grain size distributions in low carbon steels. These steels with a combination of coarse and fine grains often sacrifice much strength in order to achieve excellent ductility. In the study of Shin et al. [12], initial microstructure of ferrite and pearlite was used to produce ultrafine grained low carbon steel by the equal channel angular pressing technique. In addition, bainite starting microstructure [31] also showed a notable potential for grain 
refinement, but its refining effect is limited in some degree. At first, the mean thickness of the deformed bainitie lamella is relatively bigger than deformed lath martensite. This can be explained by the fact that deformation in bainite is more heterogeneous in comparison to the martensite. Moreover, the relative smaller distortion energy and defect density in bainite are another intrinsic limitation to the grain refinement. Nano-sized grains could be developed by deforming martensite. This is because there are large misorientations in martensite that can finely subdivide the martensite structure. Moreover, high dislocation density in martensite increases the distortion energy during the cold deformation, facilitating the formation of ultrafine grains during annealing. Furthermore, large amount of carbides uniformly precipitate in the grain boundaries due to supersaturated solid solution of $\mathrm{C}$ atom in martensite, thus preventing grain growth through pinning effect [32].
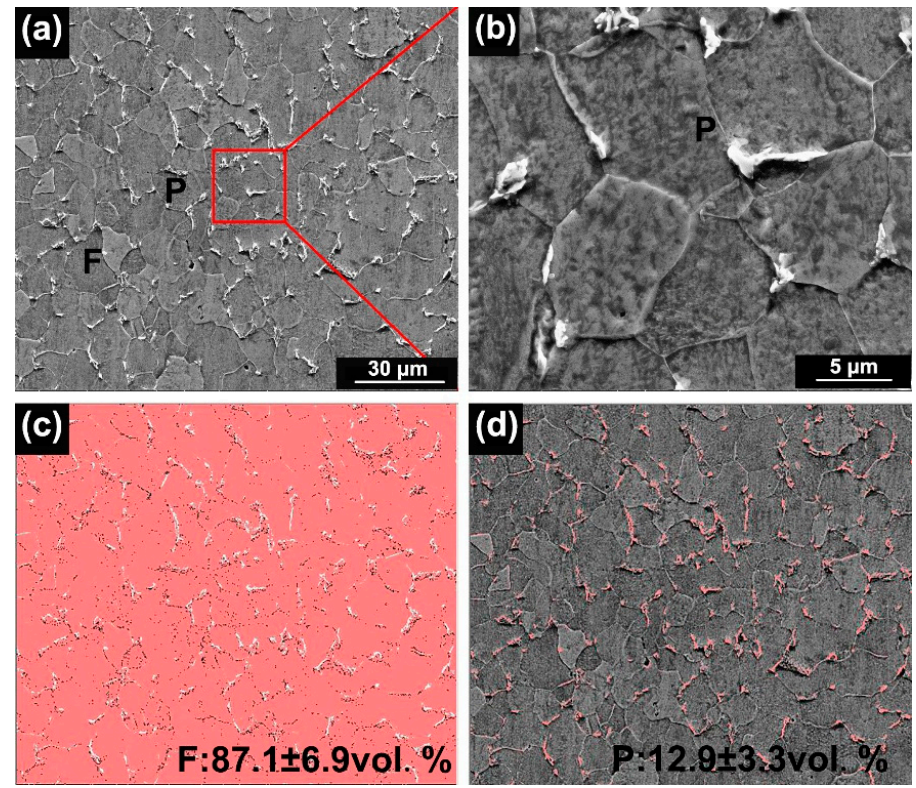

Figure 2. Original microstructure of low-carbon steel (a,b) F + P; (c) Measurement of F area; and, (d) Measurement of P area.

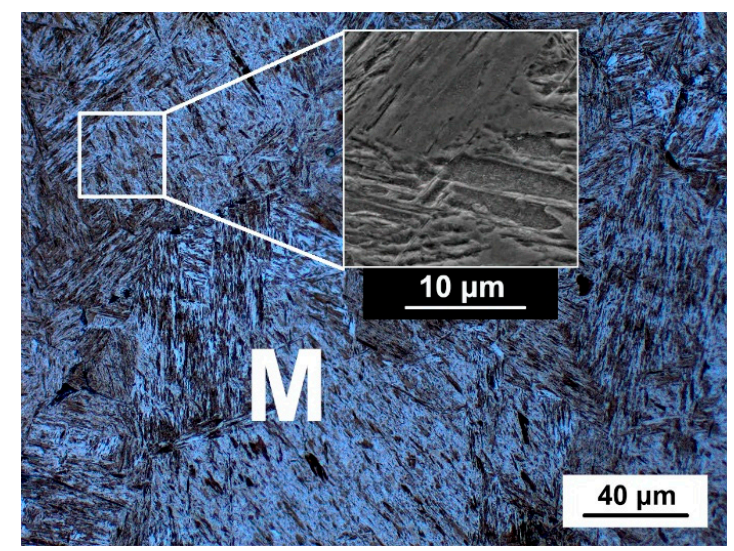

Figure 3. Martensite starting microstructure.

Figure 4 presents the SEM images showing the deformed martensite microstructure with the tand that was identified in Figure 4a,b. Lamellar dislocation cell (LDC), as the first kind substructure, showed apparently wavy flow morphology parallel to RD. The second substructure presented an irregularly bent lamellar pattern (IBL). It has already been stated that these substructures are mostly surrounded 
by high-angle grain boundaries with misorientations that are larger than $15^{\circ}[13,21,24]$, which are beneficial for the further refinement of grain. The third substructure showed kinked lath (KL) structure where martensite lath was kinked by shear bands. It is clear that the LDC substructure increases with the increase of reduction, while IBL and KL substructures decrease with the increasing reduction.
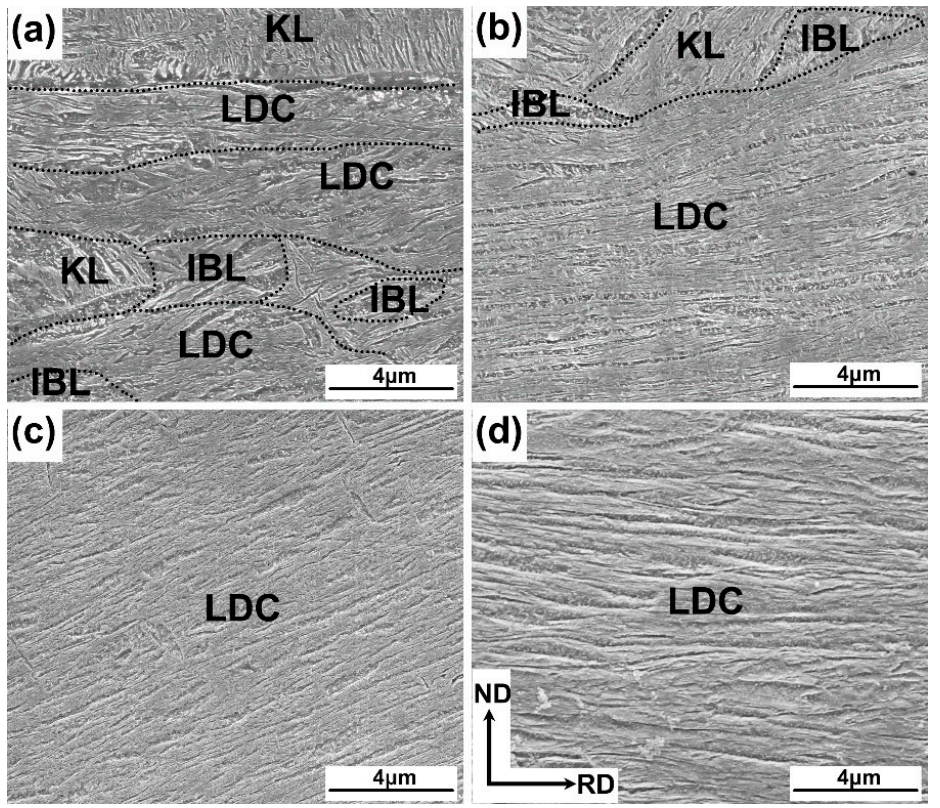

Figure 4. Scanning electron microscope (SEM) images showing the deformed martensite microstructure distinguished by three typical substructures with different reductions (a) 50\%; (b) 60\%; (c) 70\%; and, (d) $80 \%$.

Figure 5 illustrates the quantificational volume fractions of the deformed martensite with the reduction of $50 \%$ to $80 \%$ at liquid nitrogen temperature. The LDC substructure was $64.8 \%$ in the deformed microstructure, and the IBL substructure was $9.9 \%$ in a specimen cryorolled by $50 \%$ reduction. For the specimen cryorolled by $60 \%$ reduction, the volume fractions of LDC and IBL substructures were $87.8 \%$ and $5.7 \%$, respectively. With the increase of reduction amount, fully LDC substructure was obtained in the specimen cryorolled by $70 \%$ and $80 \%$ reduction. In the investigation of Ueji et al. [21,24], $50 \%$ LDC substructure was observed at 50\% cold-rolled and fully LDC substructure was obtained by $70 \%$ deformation at room temperature. When compared with the results in the present study, it demonstrates that more LDC substructure could be acquired by cryorolling martensite under the same reduction. This is because the deformation resistance severely increases with the decrease of deformation temperature, which makes the deforming force at the same reduction is bigger than that at room temperature. Thus, the morphology of martensite block inclines to the deformation indirection, showing more wavy flow morphology at liquid nitrogen temperature. Additionally, the relationship between temperature rise $\Delta T$ and strain $\varepsilon$ can be expressed as Equation (1) [33]:

$$
\int_{T_{0}}^{T_{0}+\Delta T} \rho c d T=\int_{\varepsilon_{0}}^{\varepsilon_{0}+\Delta \varepsilon} \sigma d \varepsilon \Rightarrow \Delta T=\frac{\bar{\sigma} \Delta \varepsilon}{\rho c}
$$

where $\rho$ is the density of material, $\sigma$ the true stress, $c$ the specific heat, $\Delta \varepsilon$ the interval of strain, and $\sigma$ bar the mean stress. It reveals that the temperature rise $\Delta T$ increases with the increasing strain $\varepsilon$. It reveals that the temperature rise $\Delta T$ increases with the increasing strain $\varepsilon$. However, the $\Delta T$ resulting from the plastic deformation in the deformed microstructure was restrained by the liquid nitrogen temperature in the current work. Because the atomic diffusion and the thermal activation recovery process was severely inhibited at extremely low temperature, ensuring that the vacancies and 
deformation dislocation defects were reserved and accumulated continuously. Hence, these defects were transformed into dislocation cells or substructure, leading to a severe structure deformation paralleling RD. Thus, it can inferred that fully LDC substructure could be obtained with the reduction less than $70 \%$, despite the deficiency of reduction between $60 \%$ and $70 \%$.

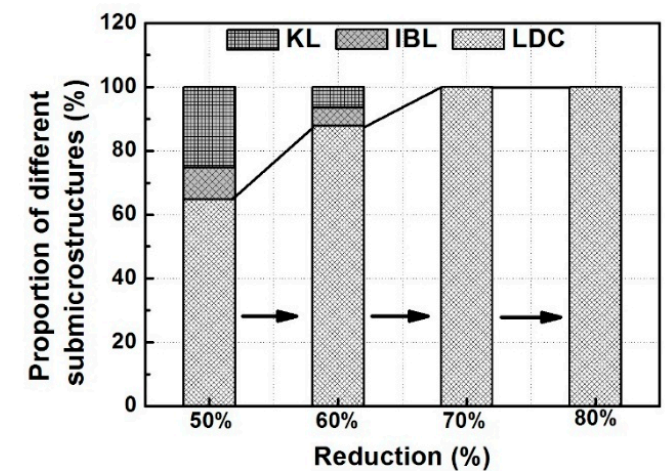

Figure 5. Percentage of different substructures at different reduction amounts.

Figure 6 presents the TEM micrographs of the specimens that were rolled at different temperature to compare the deformation dislocation distribution after rolling at liquid nitrogen and room temperatures. It is observed that the martensite lath was distinctly refined in specimen cryorolled at liquid temperature (Figure $6 \mathrm{c}$ ). The refined martensite lath is attributed to the stronger deformation resistance at liquid nitrogen temperature. Moreover, the density of intricate dislocations that were observed in the specimen rolled at liquid nitrogen temperature (Figure 6d) is much larger than that in the sample rolled at room temperature. Although it was not very clear to observe the dislocation line, the tangled dislocations were observed. Similar tangled dislocations were observed in Ref. [24]. Results in TEM confirm that deformation dislocation defects were easier to be retained and accumulated due to the suppression of dynamic recovery at liquid nitrogen temperature.
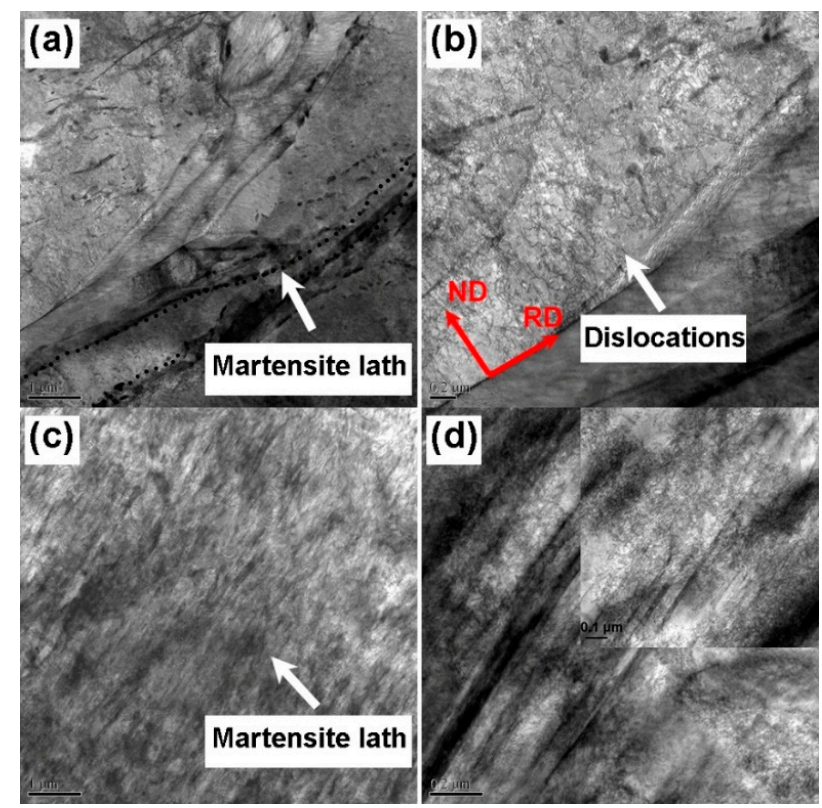

Figure 6. Transmission electron microscope (TEM) micrographs showing the morphology of rolled martensite and dislocation: $(\mathbf{a}, \mathbf{b})$ specimen rolled at room temperature; and, $(\mathbf{c}, \mathbf{d})$ specimen rolled at liquid nitrogen temperature. 
The annealed microstructures with $50-80 \%$ reduction in thickness are given in Figure 7 . It can be observed that the recrystallization microstructure mainly consisted of ultrafine ferrite grain and carbide particles. The ultrafine ferrite in equiaxial shape had distinct grain boundaries where a large amount of carbide particles was located. Figure 8 gives the XRD results, confirming that the carbide particles are $\mathrm{Fe}_{3} \mathrm{C}$. The data base entry applied in the XRD analysis is COD 201201. The precipitation of $\mathrm{Fe}_{3} \mathrm{C}$ was attributed to supersaturated solid solution of $\mathrm{C}$ in martensite starting microstructure. Besides, the carbide particles were in micro-scale and nano-scale, displaying the apparent size disparity. The complete recrystallization finished at $500{ }^{\circ} \mathrm{C}$ in the specimens cryorolled by $50-80 \%$, which was slightly lower than the lowest theoretical recrystallization temperature of $550{ }^{\circ} \mathrm{C}$, as deduced from Equation (2):

$$
T_{R}=(0.35-0.4) T_{M}
$$

where $T_{R}$ is the recrystallization temperature and $T_{M}$ the melting temperature of steel. The foremost reason accounts for the decreased recrystallization temperature is that the strain at liquid nitrogen temperature facilitates the formation and retention of defects, which act as a driving force for the formation of ultrafine grains (Figure 6d).
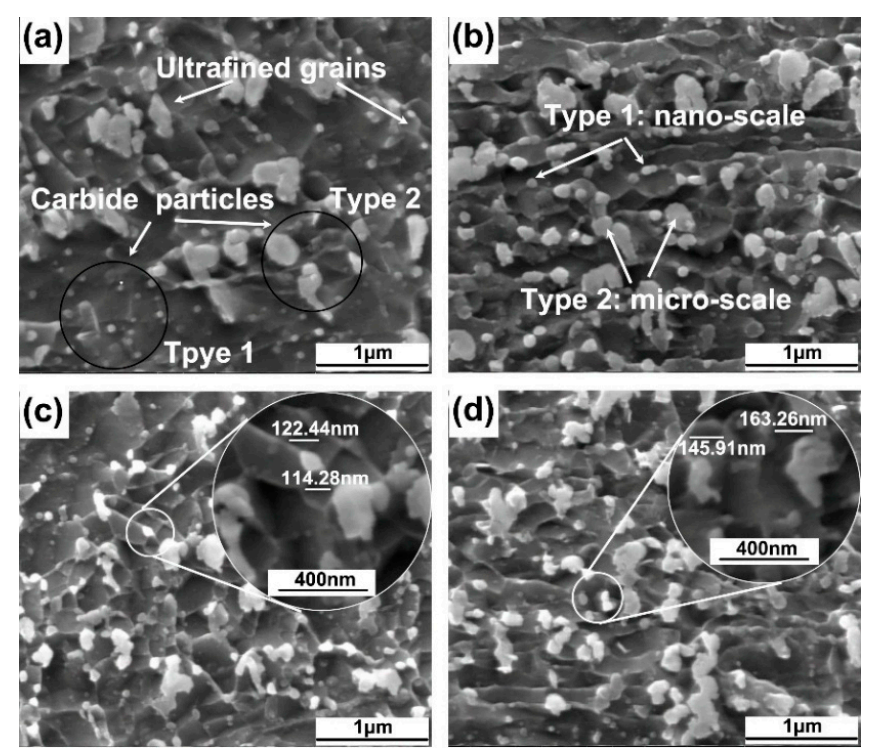

Figure 7. Recrystallization ferrite and carbide particles at different reduction amounts (a) $50 \%$; (b) $60 \%$; (c) $70 \%$; and, (d) $80 \%$.

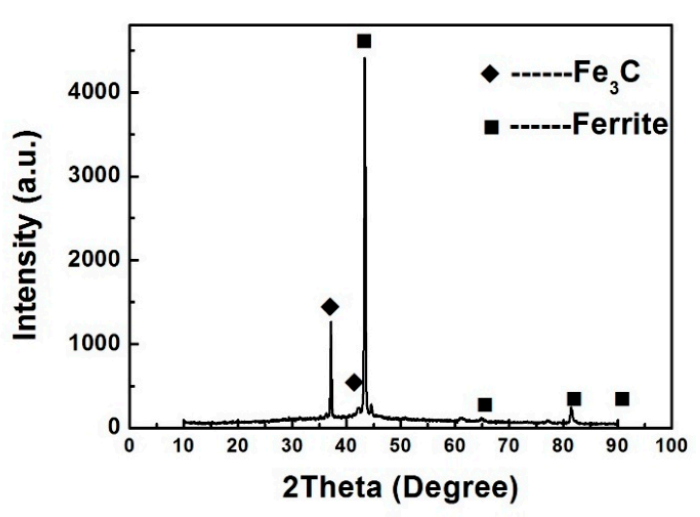

Figure 8. X-ray diffraction (XRD) results displaying the diffraction peaks of $\alpha$ phase (ferrite) and $\mathrm{X}_{3} \mathrm{C}$. 
Grain size distribution at different reductions is presented in Figure 9. The mean ferrite sizes in specimens that were cryorolled by $50-80 \%$ reductions were $161.2 \mathrm{~nm}, 148.3 \mathrm{~nm}, 132.0 \mathrm{~nm}$, and 152.3 $\mathrm{nm}$, respectively. The main size distribution range of specimen cryorolled by $50 \%$ was $100 \sim 300 \mathrm{~nm}$, while the grain distribution of 50 250 nm, 0 250 nm, and 50 300 nm dominated the grain size in the specimens cryorolled by $60 \%, 70 \%$, and $80 \%$, respectively. The fitting curve (red lines) revealed that the grain size distributions in specimens with different reductions conformed to the lognormal distribution and the square of correlation coefficient $R^{2}$ was within the scope of 0.95-0.99. According to the lognormal distribution Equation (3) [34]:

$$
y=y_{0}+\frac{A}{w x \sqrt{2 \pi}} e^{-2 \frac{\left[\ln \left(\frac{x}{x_{c}}\right)\right]^{2}}{w^{2}}}
$$

where $y_{0}$ is the offset al.ong the ordinate direction, $A$ is the area of curve formed with the $\mathrm{x}$-coordinate, $w$ is standard deviation (SD), and $x$ is the grain diameter and $\ln x_{c}$ is the arithmetic mean of $\ln x$. In the current work, the distributions of grain dimension in specimens with different reductions were described in the following Equations (4)-(7):

$$
\begin{aligned}
& \text { Reduction }=50 \%, y=-6.47+\frac{263.38}{1.38 x \sqrt{2 \pi}} e^{\frac{\left.-\left[\ln \frac{x}{2.38}\right)\right]^{2}}{3.81}} \\
& \text { Reduction }=60 \%, y=-4.55+\frac{148.47}{1.26 x \sqrt{2 \pi}} e^{\frac{\left.-\left[\ln \frac{x}{13.18}\right)\right]^{2}}{3.15}} \\
& \text { Reduction }=70 \%, y=-3.09+\frac{95.94}{1.16 x \sqrt{2 \pi}} e^{\frac{\left.-\left[\ln \frac{x}{9.98}\right)\right]^{2}}{2.71}} \\
& \text { Reduction }=80 \%, y=-3.79+\frac{127.53}{1.24 x \sqrt{2 \pi}} e^{\frac{\left.-\left[\ln \frac{x}{12.53}\right)\right]^{2}}{3.12}}
\end{aligned}
$$

The SD decreased firstly from 1.38 to 1.16 with the reduction increase from $50 \%$ to $70 \%$, and then increased to 1.24 with the reduction from $70 \%$ to $80 \%$. This means that the distribution range of ferrite grain size tends to concentration with the increase of reduction. However, there were valley values in SD corresponding to the specimen that was cryorolled by $70 \%$. With the increase of reduction to $80 \%$, some abnormal large grains appeared due to the secondary recrystallization. The similar secondary recrystallization phenomenon was explained in Ma et al. [35] research. Both the mean grain size and the distribution range of ferrite increased, meaning that the size of ferrite grain became larger. Therefore, the size of ferrite grains became the most uniform at the reduction of $70 \%$.

When comparing with other works at room temperature, the size of ultrafine equiaxed grains at liquid nitrogen temperature was sharply reduced. The results in the current work demonstrate that the ultrafine grain can be further refined by adjusting the deformation temperature from room temperature to the liquid nitrogen temperature. This is because that the restraint of dynamic recovery process, for example, the cross slips of screw dislocations and climbs of edge dislocations, during cryorolling at liquid nitrogen temperatures results in a high dislocation density. There are more nucleation sites during annealing, resulting in a finer grain structure. Moreover, the deformed martensite lath was refined in liquid nitrogen temperature due to the stronger deformation resistance (Figure 6c). The recrystallization temperature is reduced via cryorolling process, favoring the formation of smaller grains. The decrease of grain size with the increase of reduction from $50 \%$ to $70 \%$ is mainly because of more nucleation sites induced by heavier deformation. However, the increasing grain size in specimens that were cryorolled from $70 \%$ to $80 \%$ reduction can be explained by the accumulated distortion energy due to heavier strain of $80 \%(\varepsilon=1.8)$ at liquid nitrogen temperature. The ferrite grains become unstable because of the larger accumulated distortion energy at $80 \%$ reduction, resulting in the secondary recrystallization of ferrite during the annealing at $500^{\circ} \mathrm{C}$. 

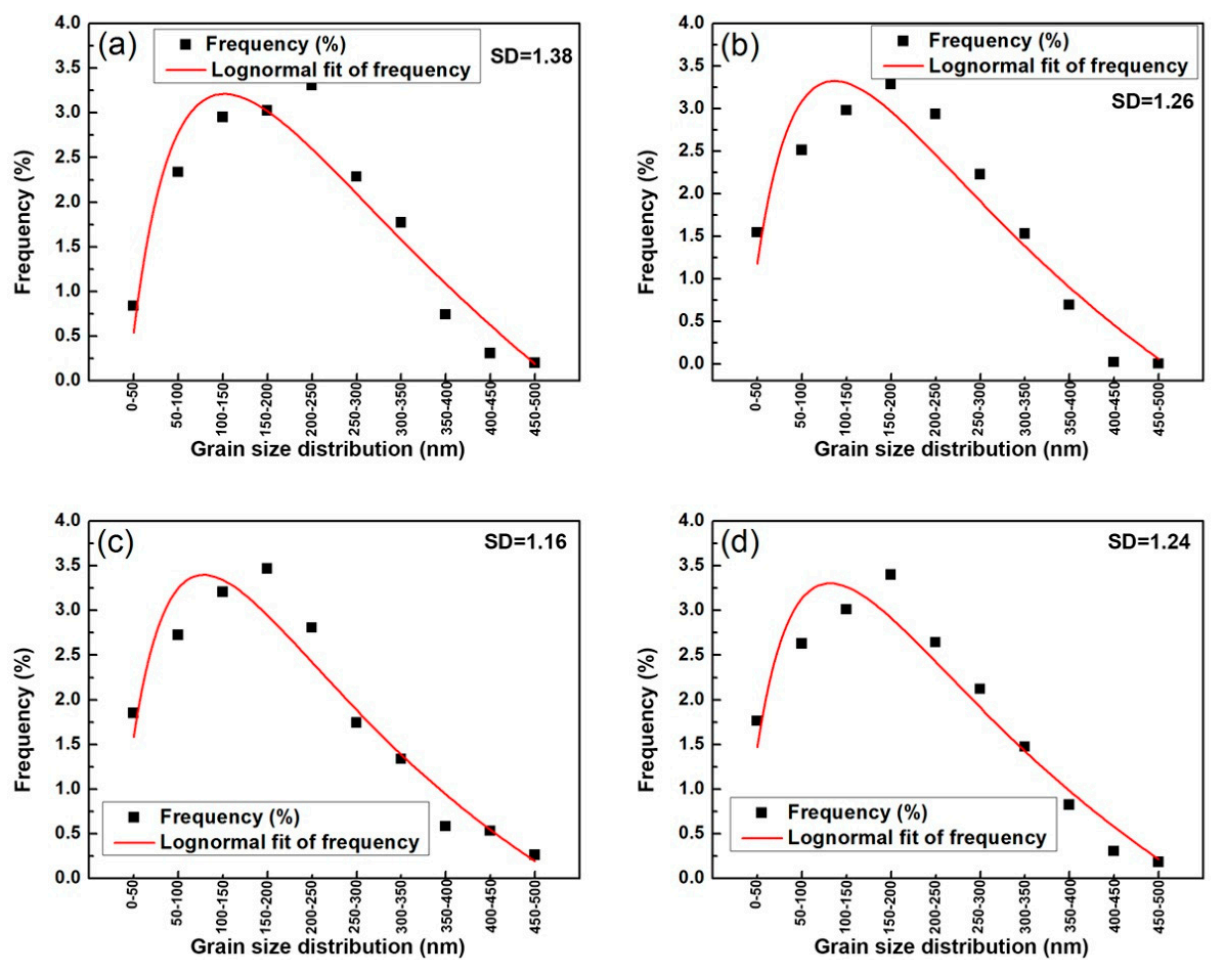

Figure 9. Distributions of ferrite size at different reductions (a) 50\%, (b) 60\%, (c) $70 \%$, and (d) $80 \%$.

\subsection{Mechanical Property}

The stress-strain curves of specimens that were cryorolled at different reductions and annealed at $500{ }^{\circ} \mathrm{C}$ for $30 \mathrm{~min}$ are shown in Figure 10. The tensile strength increased first with the increasing reduction from $50 \%$ to $70 \%$, and then decreased with the increase of reduction from $70 \%$ to $80 \%$. The optimal balance between the strength and ductility was reached in specimen cryorolled by $70 \%$ reduction and subsequent annealing. The strength of specimen cryorolled by $70 \%$ reduction was 978.1 MPa with an elongation of $12.3 \%$. The strength was improved about $543.1 \mathrm{MPa}$ with reasonable sacrifice in ductility when compared with the original low-carbon steel. When compared with the results in author's previous study [26,36], the mechanical property in specimen cryorolled by $50 \%$ and annealed at $500{ }^{\circ} \mathrm{C}$ for $30 \mathrm{~min}$ were almost consistent with that in specimen cold-rolled by $50 \%$ and annealed at $550{ }^{\circ} \mathrm{C}$ for $30 \mathrm{~min}$. The average size of ferrite in the current work was smaller than that of specimen cold rolled by $50 \%$ and annealed at $550{ }^{\circ} \mathrm{C}$ for $30 \mathrm{~min}$ due to the smaller recrystallization temperature in specimen cryorolled by $50 \%$. In addition, the reason for the peak value of strength in specimen cryorolled by $70 \%$ is accordant with the changing of grain size. When compared to the original materials, the bad ductility in ultrafine-grain could be ascribed to their poor work-hardening capacity induced by size effect, poorer ability to accumulate dislocations in dinky grains. Besides, the negative influence of the large size $\mathrm{Fe}_{3} \mathrm{C}$ particles cannot be overlooked.

In the investigations of Xiong et al. [37,38], cryorolling was also employed to fabricate austenitic stainless steels (AISI $316 \mathrm{LN}$ and Fe-25Cr-20Ni). Several significant similarities between the results in the present study and references $[37,38]$ can be summarized. Firstly, the strength was greatly improved with the sharp decrease of elongation in the tested steels. Secondly, the grains after cryorolling was apparently refined when compared with the original grains. Finally, a large amount of dislocations was observed in the cryorolled specimens. The differences between above researches and results in the current work are more interesting in optimizing the fabrication technology of ultra-fine grains. At first, the initial microstructures before cryorolling and the final microstructures were different. Single-phase austenite initial microstructure was used before cryorolling at liquid nitrogen temperature 
in refs $[37,38]$, and the final deformation-induced martensite microstructure was obtained during the cryorolling process. In the present study, martensite starting microstructure was cryorolled to obtain the ultrafine recrystallized ferrite grains after low-temperature annealing in a low-carbon steel. In addition, the improvement of strength with the strain in the cryorolled austenitic stainless steels was attributed to the increasing refined deformation-induced martensite microstructure and larger amount of defects. However, in the present study, the increase of strength in the ultrafine grained low-carbon steel was ascribed to the nano/micro-scale ferrite grains and dispersed $\mathrm{Fe}_{3} \mathrm{C}$ particles. Moreover, the strength of ultrafine grained low-carbon steel did not increase with the strain as expected due to the secondary recrystallization phenomenon in the specimen that was cryorolled by $70 \%$. No secondary recrystallization phenomenon was reported in the austenitic stainless steels. That is probably because the relative smaller accumulated distortion energy in the austenite initial microstructure of the austenitic stainless steels.

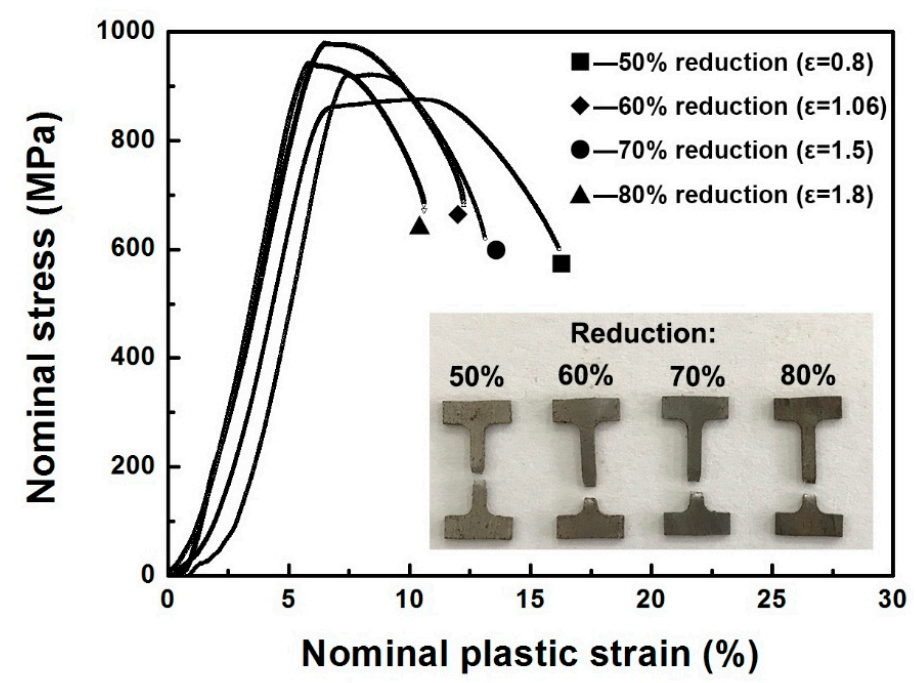

Figure 10. Stress-strain curves of specimens with different reductions.

\subsection{Fracture Morphology}

Fracture morphologies of specimens cryorolled at different reductions and annealed at $500{ }^{\circ} \mathrm{C}$ for $30 \mathrm{~min}$ are shown in Figure 11. Large amount of dimples were observed in the four specimens, representing that the main ductile fracture pattern.

In summary, ultrafine grain structured low carbon steel was successfully fabricated by cryorolling martensite starting microstructure at liquid nitrogen temperature. Ultrafine grain low-carbon steel, with a high strength of $978.1 \mathrm{MPa}$ and an elongation of $12.3 \%$, as well as a mean grain size of $132.0 \mathrm{~nm}$ was produced by cryorolling and annealing of martensite. Figure 12 illustrates the relationship between reduction and mean grain size, $\mathrm{SD}$, and tensile strength. The decrease of ferrite grain size from $50 \%$ to $70 \%$ reduction is mainly attributed to the suppression of dynamic recovery during cryorolling and more nucleation sites for the formation of ultrafine grains. However, when the reduction increases to $80 \%$, the accumulated larger distortion energy induces the secondary recrystallization of ferrite. Therefore, there are a peak value and a valley value in the relationship between reduction and mean grain size, $\mathrm{SD}$, and tensile strength. 

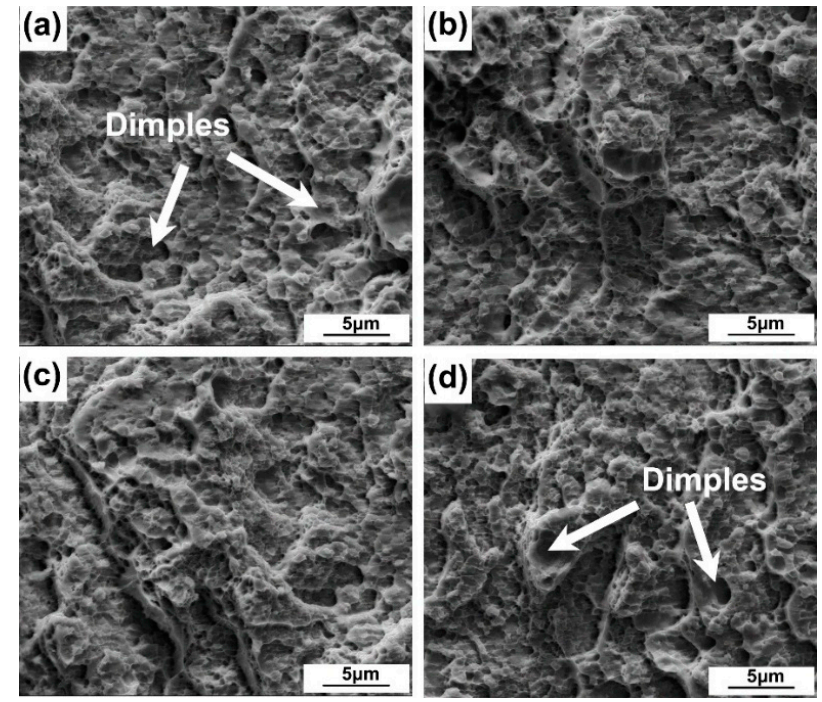

Figure 11. Tensile fractures of specimens cryorolled by (a) $50 \%$, (b) $60 \%$, (c) $70 \%$, and (d) $80 \%$ and then annealed at $500{ }^{\circ} \mathrm{C}$ for $30 \mathrm{~min}$.

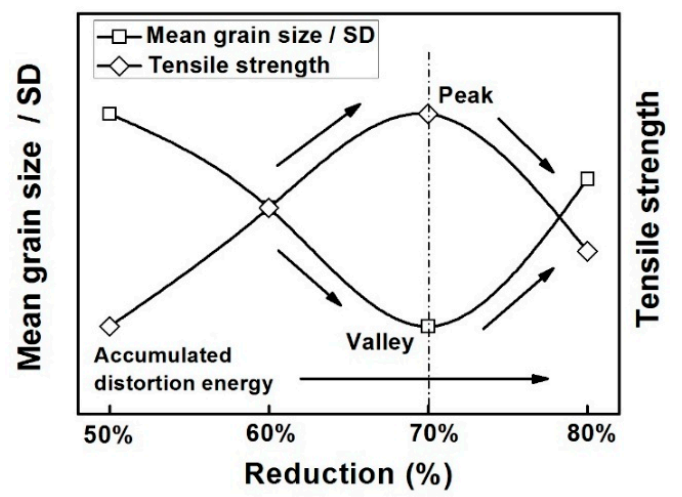

Figure 12. Schematic diagram of the relationship between reduction and mean grain size, SD, and tensile strength.

\section{Conclusions}

Low-carbon steel was subjected to multi-pass cryorolling with different reductions of $50 \%, 60 \%$, $70 \%$, and $80 \%$ at liquid nitrogen temperature and annealed at $500{ }^{\circ} \mathrm{C}$ for $30 \mathrm{~min}$. Microstructure evolution was examined by optical microscopy and scanning electron microscope. The dislocation distribution after rolling was observed using a transmission electron microscope (TEM). Precipitates were determined by X-ray diffraction and the mechanical property was measured by an electronic universal tensile machine. The following conclusions can be drawn:

(1) There are peak value and valley value in the strength and grain size of ferrite with the increase of reduction from $50 \%$ to $80 \%$, respectively. The further growth of recrystallization ferrite grains at $80 \%$ is attributed to the secondary recrystallization that was activated by heavier accumulated distortion energy at large reduction.

(2) The distribution of ferrite grains becomes more uniform with increasing reduction from $50 \%$ to $70 \%$. The amount of lamellar dislocation cell substructure increases with the reduction due to the stronger deformation resistance as well as the inhabitation of atomic diffusion and thermal activation recovery process at liquid nitrogen temperature. 
(3) Ultrafine-grain structured steel is manufactured by cryorolling and the subsequent annealing of martensite. Optimal balance between strength $(978.1 \mathrm{MPa})$ and adequate ductility $(12.3 \%)$ is obtained in the specimen that was cryorolled by $70 \%$ reduction and annealed at $500{ }^{\circ} \mathrm{C}$ for $30 \mathrm{~min}$. The smallest mean ferrite size is about $132.0 \mathrm{~nm}$.

Author Contributions: Q.Y. doctoral student, conducted experiments, analyzed the data and wrote the paper; G.X. supervisor, conceived and designed the experiments; S.L. lecturer, conducted experiments and analyzed the data; M.L. master students, conducted experiments and analyzed the data; H.H. doctoral students, conducted experiments and analyzed the data; G.L. polished the paper.

Funding: The Major Projects of Technology Innovation of Hubei Province (2017AAA116), the National Natural Science Foundation of China (NSFC) (No. 51274154), the National Nature Science Foundation of China (No. 51704217) and Hebei Joint Research Fund for Iron and Steel (E2018318013).

Acknowledgments: The authors gratefully acknowledge the financial supports from The Major Projects of Technology Innovation of Hubei Province (2017AAA116), the National Natural Science Foundation of China (NSFC) (No. 51274154), the National Nature Science Foundation of China (No. 51704217) and Hebei Joint Research Fund for Iron and Steel (E2018318013).

Conflicts of Interest: The authors declare no conflict of interest. The founding sponsors had no role in the design of the study; in the collection, analyses, or interpretation of data; in the writing of the manuscript, and in the decision to publish the results.

\section{References}

1. Eskandari, M.; Najafizadeh, A.; Kermanpur, A.; Karimi, M. Potential application of nanocrystalline 301 austenitic stainless steel in lightweight vehicle structures. Mater. Des. 2009, 30, 3869-3872. [CrossRef]

2. Koch, C.C. Optimization of strength and ductility in nanocrystalline and ultrafine grained metals. Scr. Mater. 2003, 49, 657-662. [CrossRef]

3. Raabe, D.; Ponge, D.; Dmitrieva, O.; Sander, B. Nanoprecipitate-hardened 1.5 GPa steels with unexpected high ductility. Scr. Mater. 2009, 60, 1141-1144. [CrossRef]

4. Chen, X.H.; Lu, J.; Lu, L.; Lu, K. Tensile properties of a nanocrystalline $316 \mathrm{~L}$ austenitic stainless steel. Scr. Mater. 2005, 52, 1039-1044. [CrossRef]

5. Lu, K. Making strong nanomaterials ductile with gradients. Science 2014, 345, 1455-1457. [CrossRef] [PubMed]

6. Zhou, X.; Li, X.Y.; Lu, K. Enhanced thermal stability of nanograined metals below a critical grain size. Science 2018, 6388, 526-530. [CrossRef] [PubMed]

7. Dao, M.; Lu, L.; Asaro, R.J.; Hosson, J.T.M.D.; Ma, E. Toward a quantitative understanding of mechanical behavior of nanocrystalline metals. Acta Mater. 2007, 55, 4041-4065. [CrossRef]

8. Zhao, L.J.; Park, N.; Tian, Y.Z.; Chen, S.; Shibata, A.; Tsuji, N. Novel thermomechanical processing methods for achieving ultragrain refinement of low-carbon steel without heavy plastic deformation. Mater. Res. Lett. 2017, 5, 61-68. [CrossRef]

9. Tsuji, N.; Ueji, R.; Minamino, Y. Nanoscale crystallographic analysis of ultrafine grained IF steel fabricated by ARB process. Scr. Mater. 2002, 47, 69-76. [CrossRef]

10. Wang, B.F.; Sun, J.Y.; Zou, J.D.; Vincent, S.; Li, J. Mechanical responses, texture and microstructural evolution of high purity aluminum deformed by equal channel angular pressing. J. Cent. South Univ. 2015, 22, 3698-3704. [CrossRef]

11. Matsybara, K.; Miyahara, Y.; Horita, Z.; Langdon, T.G. Developing superplasticity in a magnesium alloy through a combination of extrusion and ECAP. Acta Mater. 2003, 51, 3073-3084. [CrossRef]

12. Shin, D.H.; Kim, B.C.; Park, K.; Kim, Y.S. Microstructure evolution in a commercial low carbon steel by equal channel angular pressing. Acta Mater. 2000, 48, 2247-2255. [CrossRef]

13. Tsuji, N.; Shiotsuki, K.; Saito, Y. Super plasticity of ultra-fine grained Al-Mg alloy produced by accumulative roll-bonding. Mater. Trans. JIM 1999, 40, 765-771. [CrossRef]

14. Tsuji, N.; Ueji, R.; Saito, Y. Ultra-fine grains in ultralow carbon IF steel highly strained by ARB. Mater. Jpn. 2000, 39, 961-966. (In Japanese) [CrossRef] 
15. Saito, Y.; Utsunomiya, H.; Tsuji, N.; Sakai, T. Novel ultra-high straining process for bulk materials-development of the accumulative roll-bonding (ARB) process. Acta Mater. 1999, 47, 579-583. [CrossRef]

16. Belyakov, A.; Sakika, Y.; Hara, T.; Kimura, Y.; Tsuzaki, K. Annealing behavior of submicrocrystalline oxide-bearing iron produced by mechanical alloying. Metall. Mater. Trans. A 2003, 34, 131-138. [CrossRef]

17. Takaki, S.; Kawasaki, K.; Kimura, Y. Ultrafine Grained Materials; Mishra, R.S., Ed.; The Minerals, Metals \& Materials Society (TMS): Warrendale, PA, USA, 2000; pp. 247-255.

18. Sabbaghianrad, S.; Kawasaki, M.; Langdon, T.G. Microstructural evolution and the mechanical properties of an aluminum alloy processed by high-pressure torsion. J. Mater. Sci. 2012, 47, 7789-7795. [CrossRef]

19. Horita, Z.; Smith, D.; Furukwa, M.; Nnemoto, M.; Valiev, R.Z.; Langdon, T.G. An investigation of grain boundaries in submicrometer-grained Al-Mg solid solution alloys using high-resolution electron microscopy. J. Mater. Res. 1996, 11, 1880-1890. [CrossRef]

20. Ivanisenko, Y.; Wunderlich, R.K.; Valiev, R.Z.; Fecht, H.J. Annealing behaviour of nanostructured carbon steel produced by severe plastic deformation. Scr. Mater. 2003, 49, 947-952. [CrossRef]

21. Tsuji, N.; Ueji, R.; Minamino, Y.; Saito, Y. A new and simple process to obtain nano-structured bulk low-carbon steel with superior mechanical property. Scr. Mater. 2002, 46, 305-310. [CrossRef]

22. Hosseini, S.M.; Alishahi, M.; Najafizadeh, A.; Kermanpur, A. The improvement of ductility in nano/ultrafine grained low carbon steels via high temperature short time annealing. Mater. Lett. 2012, 74, 206-208. [CrossRef]

23. Ashrafi, H.; Najafizadeh, A. Fabrication of the ultrafine grained low carbon steel by cold compression and annealing of martensite. Trans. Indian Inst. Met. 2016, 8, 1467-1473. [CrossRef]

24. Ueji, R.; Tsuji, N.; Minamino, Y.; Koizumi, Y. Ultragrain refinement of plain low carbon steel by cold rolling and annealing of martensite. Acta Mater. 2002, 50, 4177-4189. [CrossRef]

25. Bao, Y.Z.; Adachi, Y.; Toomine, Y.; Xu, P.G.; Suzuki, T.; Tomota, Y. Dynamic recrystallization by rapid heating followed by compression for a 17Ni-0.2C martensite steel. Scr. Mater. 2005, 53, 1471-1476. [CrossRef]

26. Tian, J.Y.; Xu, G.; Liang, W.C.; Yuan, Q. Effect of annealing on the microstructure and mechanical properties of a low-carbon steel with ultrafine grains. Metallogr. Microstruct. Anal. 2017, 6, 233-239. [CrossRef]

27. Li, X.; Jing, T.F.; Lu, M.M.; Zhang, J.W. Microstructure and mechanical properties of ultrafine lath-shaped low carbon steel. J. Mater. Eng. Perform. 2012, 21, 1496-1499. [CrossRef]

28. Hamad, K.; Ko, Y.G. Annealing characteristics of ultrafine grained low-carbon steel processed by differential speed rolling method. Metall. Mater. Trans. A 2016, 47A, 2319-2334. [CrossRef]

29. Alizamini, H.A.; Militzer, M.; Poole, W.J. A novel technique for developing bimodal grain size distributions in low carbon steels. Scr. Mater. 2007, 57, 1065-1068. [CrossRef]

30. Wang, T.S.; Zhang, F.C.; Zhang, M.; Lv, B. A novel process to obtain ultrafine-grained low carbon steel with bimodal grain size distribution for potentially improving ductility. Metall. Mater. Trans. A 2008, 485, 456-460. [CrossRef]

31. Hamzeh, M.; Kermanpur, A.; Najafizadeh, A. Fabrication of the ultrafine-grained ferrite with good resistance to grain grow than devaluation of its tensile properties. Mater. Sci. Eng. A 2014, 593, 24-30. [CrossRef]

32. Dong, Z.Q.; Jiang, B.; Mei, Z.; Zhang, C.L.; Zhou, L.Y.; Liu, Y.Z. Effect of carbide distribution on the grain refinement in the steel for large-size bearing ring. Steel Res. Int. 2016, 87, 745-751. [CrossRef]

33. Kapoor, R.; Nasser, S.N. Determination of temperature rise during high strain rate deformation. Mech. Mater. 1998, 27, 1-12. [CrossRef]

34. Olyaeefar, B.; Kandjani, S.A.; Asgari, A. Classical modeling of grain size and boundary effects in polycrystalline perovskite solar cells. Sol. Energy Mater. Sol. Cells 2018, 180, 76-82. [CrossRef]

35. Wang, Y.M.; Chen, M.W.; Zhou, F.H.; Ma, En. High tensile ductility in a nanostructured metal. Nature 2002, 419, 912-914. [CrossRef] [PubMed]

36. Yuan, Q.; Xu, G.; Tian, J.Y.; Liang, W.C. The recrystallization behavior in ultrafine-grained structure steel fabricated by cold rolling and annealing. Arab. J. Sci. Eng. 2017, 42, 4771-4777. [CrossRef] 
37. Xiong, Y.; Yue, Y.; Lu, Y.; He, T.T.; Fan, M.X.; Ren, F.Z.; Cao, W. Cryorolling impacts on microstructure and mechanical properties of AISI 316 LN austenitic stainless steel. Mater. Sci. Eng. A 2018, 709, 270-276. [CrossRef]

38. Xiong, Y.; He, T.T.; Wang, J.B.; Lu, Y.; Chen, L.F.; Ren, F.Z.; Liu, Y.L.; Volinsky, A.A. Cryorolling effect on microstructure and mechanical properties of Fe-25Cr-20Ni austenitic stainless steel. Mater. Des. 2015, 88, 398-405. [CrossRef] 